\title{
Roteiros Possíveis: relato de uso de um Produto Educacional no espaço de Educação Profissional e Tecnológica
}

\begin{abstract}
Resumo:
O espaço educacional da Educação Profissional e Tecnológica é o cenário deste relato de experiência, que busca unir educadores e educandos e a experiência estética por meio de um Produto Educacional. O problema de pesquisa foi constituído a partir da premissa freireana a qual sustenta que para realizar uma educação integral pressupõe-se, entre outras questões, a experiência estética. Desta forma, desenvolveu-se um material textual no formato de guia disponibilizado como recurso pedagógico para a criação de exposições com a produção dos educandos, o qual foi posto em uso com diferentes turmas de variados níveis educativos, resultando em mostras que puderam dar a dimensão da importância da experiência estética no referido contexto educativo.
\end{abstract}

\section{Palavras-chave:}

Educação Profissional e Tecnológica. Experiência estética. Produto Educacional.

\begin{abstract}
:
The educational space of Professional and Technological Education is the scenario of this report, which seeks to unite educators and students and the aesthetic experience through an educational product. The research problem was constituted from the Freirean premise which sustains that, in order to carry out a comprehensive and integrate education, aesthetic experience is needed, among other issues. In this way, a textual material was developed in the form of a guide made available as a pedagogical resource for the creation of exhibitions with the production of students, which was put in practice with different classes of varied educational levels, resulting in exhibitions that gave the dimension and the importance of aesthetic experience in the referred educational context.
\end{abstract}

\section{Keywords:}

Professional and Technological Education. Aesthetic experience. Educational Product.

* Mestra em Educação Profissional e Tecnológica (IFRS - campus Porto Alegre). Professora de Artes do IFRS - campus Restinga. E-mail: angela.cagliari@restinga.ifrs.edu.br. ORCID iD: http://orcid.org/0000-0003-0417-967X. 


\section{Introdução}

O relato de experiência aqui apresentado é um dos resultados advindos da pesquisa de mestrado em Educação Profissional e Tecnológica (EPT) chamada "Roteiros Possíveis: criando exposições no espaço de Educação Profissional e Tecnológica”. A intenção é apresentar como o Produto Educacional (PE) desenvolvido durante o mestrado foi utilizado em aula por docentes atuantes na rede de ensino federal, mais especificamente no campus Porto Alegre do Instituto Federal do Rio Grande do Sul (IFRS), no ano de 2019.

O problema de pesquisa residiu na investigação do espaço escolar de EPT como espaço de experiência estética, pressupondo esta como parte fundamental na formação integral dos sujeitos (FREIRE; SHOR, 1986). A partir desta premissa, foi proposta a reflexão sobre a experiência estética nos espaços escolares de EPT tendo como objetivo principal criar e aplicar um PE que relacionasse recursos museológicos, o espaço educacional de EPT e seus sujeitos, educadores e educandos.

O início do processo se deu a partir da verificação e análise de imagens fotográficas disponíveis nos arquivos de comunicação do campus Porto Alegre em concomitância com a pesquisa bibliográfica. Em seguida, constatando que o espaço fora das salas de aula era utilizado apenas em eventos como as feiras de iniciação científica, iniciou-se a elaboração de um material textual no formato de guia, que viria a se tornar o PE. "Roteiros Possíveis: criando exposições no espaço de Educação Profissional e Tecnológica" foi pensado para ser um material atrativo e interdisciplinar sobre como desenvolver uma exposição fazendo uso de produções de educandos realizadas em sala de aula, sem restrição de componente curricular. Buscou-se, com esse recurso educacional, ressignificar o espaço escolar de EPT por meio da experiência estética de seus sujeitos, como parte formativa de educandos e educadores a fim de complementar a experiência educativa de modo a compreenderem o sentido de suas vidas e seus papeis sociais (GADOTTI, 1991, 2010).

Partindo da visão freireana em que seres humanos são indivíduos histórico-sociais, sujeitos inacabados, com capacidade para construírem e reconstruírem a si mesmos e a história através de suas ações transformadoras das realidades das quais fazem parte, buscou-se com o PE, criar possibilidades de experiências estéticas, defendendo a EPT como educação integral. Ao propor uma educação integral para a transformação social, é preciso falar na educação possível pela experiência estética. Afinal, a vida se dá além das questões primais, da técnica, da operacionalização do cotidiano; ela também se realiza nas relações com o sensível, nos encontros estéticos, no que nos toca, no que nos modifica (LARROSA, 2002). Em suma, a emancipação humana ou a autonomia dos educandos se realiza nas relações sociais, na articulação entre saberes práticos e teóricos, e dentro desses saberes está a educação sensível, onde reside a experiência estética.

Historicamente, a concepção de educação profissional no Brasil favoreceu justamente um modelo que, ao invés de promover a formação crítica, ética e estética, realizou a manutenção do status quo da classe dominante, por meio de uma pedagogia focada na lógica de mercado. Ramos (2011) reforça a importância da compreensão histórico-social dos seres humanos para o desenvolvimento da integralidade na esfera educativa. Desse forma, a educação integral só faz sentido se for entendida a partir da concepção de formação que almeja e proporciona a omnilateralidade dos sujeitos, ou seja, busca integrar no processo educativo todas as dimensões da vida dos educandos visando diminuir as diferenças entre os oprimidos e os opressores: a educação como emancipadora de sujeitos (FREIRE, 1988).

Como parte das camadas que constituem o ser humano, a experiência estética na educação pode promover aberturas para compreender o outro ao acessar novas interpretações do eu no mundo e do mundo em mim (HERMANN, 2002). Portanto, parte-se do pressuposto freireano que a educação implica em ética e estética de modo indissociável, e esta pesquisa através do PE busca atenuar as mencionadas dicotomias historicamente dadas no mundo do trabalho. 


\section{Desenvolvimento do Produto Educacional}

"Roteiros Possíveis: criando exposições no espaço de Educação Profissional e Tecnológica"1 é categorizado como material textual. A elaboração do guia baseado nos três eixos de Kaplún (2003) foi aliado à vontade de desenvolver um material que pudesse ser utilizado por professores e estudantes em diferentes áreas do conhecimento, não ficando restrito aos componentes curriculares que tradicionalmente trabalham com visualidades, como as linguagens artísticas. O objetivo final do uso do guia esteve vinculado à formação integral humana por meio da materialização de uma exposição com potencialidade de experiência estética, capaz de transformar ou alterar significados que educandos e educadores dão aos processos de ensino-aprendizagem.

Para a criação de um material, segundo Kaplún (2003), é preciso pesquisar a temática e realizar diagnósticos: ler sobre o tema, apropriar-se dos conceitos, identificar e conhecer o universo dos sujeitos a quem o material educativo é destinado, este seria o chamado eixo conceitual, uma espécie de aventura da criação, de processo de descobertas. Juntamente, temos o eixo pedagógico, como articulador de possibilidades dos outros dois eixos (conceitual e comunicacional) a partir de ações tais como conhecer os educandos e suas percepções sobre o assunto, para se partir do que já é conhecido, a fim de realizar o diagnóstico, o qual consiste em traçar os caminhos possíveis para o destino que se escolheu. O eixo pedagógico pretende provocar conflitos conceituais, afetivos, comportamentais, deseja ser experiência (LARROSA, 2018). O terceiro e último elemento é o eixo comunicacional, designado como a etapa artística, onde se pode jogar, brincar com as possibilidades do material.

No quesito comunicacional, escolheu-se como inspiração visual a obra do artista francês Henri Matisse (1869-1954) (Figura 1). No fim da vida, Matisse já com os movimentos limitados pela idade, substituiu a pintura como técnica artística por recortes de papeis coloridos que eram dispostos no espaço da folha criando composições por meio de colagens. A opção por essa técnica é simbólica, pois evidencia os pares figura/fundo e espaço preenchido/vazio, podendo ser associado ao processo educativo como uma reflexão-ação que objetive a superação da lógica binária, que não encerre as possibilidades e sim trabalhe na união desses pares, deixando o porvir surgir.

Ao usar a simbologia da colagem no PE, desejou-se diminuir as fragmentações, criar momentos dentro do espaçotempo $o^{2}$ de EPT historicamente tão rígido e tecnicista, permitindo que educandos vejam seus trabalhos de outra forma, pois ao expor para o "mundo" fora da sala de aula, estão se colocando por meio de seus escritos, seus experimentos, suas imagens e ressignificando-os. Com o "Roteiros Possíveis", procurou-se dar visibilidade ao cotidiano, ao que fica comumente confinado ao microcosmo da sala de aula para que a sensibilização estética possa existir, para que algo potente ocorra quando os educandos que produziram a exposição tenham uma experiência estética, um novo entendimento, uma nova perspectiva ou uma suspensão das certezas para elaborar algo novo, a partir de um novo olhar. O PE almejou dar algumas direções para que seja montada uma exposição, mas os processos, os desvios, os atalhos dessa jornada são próprios de cada grupo e dos sujeitos que o compõem.

"Roteiros Possíveis: criando exposições no espaço de Educação Profissional e Tecnológica” foi desenvolvido em formato PDF para ser disponibilizado gratuitamente em repositório virtual com possibilidade de impressão, aos que desejarem uma cópia física do PE. O eixo pedagógico do guia é composto dos itens básicos de uma publicação: apresentação, introdução, objetivos. Em seguida, como parte do desenvolvimento conceitual, de modo didático e simples, explorou-se com linguagem acessível ao meio escolar o que

\footnotetext{
1. CAGLIARI, Angela Zanotelli; ZUCOLOTTO, Andréia Modrzejewski. Roteiros possíveis: criando exposições no espaço de Educação Profissional e Tecnológica. 2019. Produto Educacional (Mestrado Profissional em Educação Profissional e Tecnológica) - Instituto Federal de Educação, Ciência e Tecnologia do Rio Grande do Sul, Porto Alegre, 2019. Disponível em: https://educapes.capes.gov.br/ handle/capes/553944. Acesso em: 4 jun. 2020.

2. Alves (2001) debruça-se sobre o cotidiano em seus estudos sobre o espaço e o tempo escolares, criando um novo termo, espaçotempo, entendido como a dimensão material do currículo. O espaçotempo é múltiplo e complexo, de relações e sujeitos que aprendem e ensinam múltiplos conteúdos de igualmente múltiplas maneiras.
} 
expor, por que expor e como materializar a ideia da exposição, para que então fossem sugeridos os roteiros, que dão sugestões e exemplos para concretização da mostra. Ao fim, há um glossário com termos que são próprios do universo museológico e outras definições que dentro do contexto expositivo tomam significados diferentes, julgando serem importantes para uma melhor compreensão do ato de expor. As sugestões de leitura servem como apoio para os educadores e educandos que desejarem se aprofundar em temas da área de Museologia e exposições.

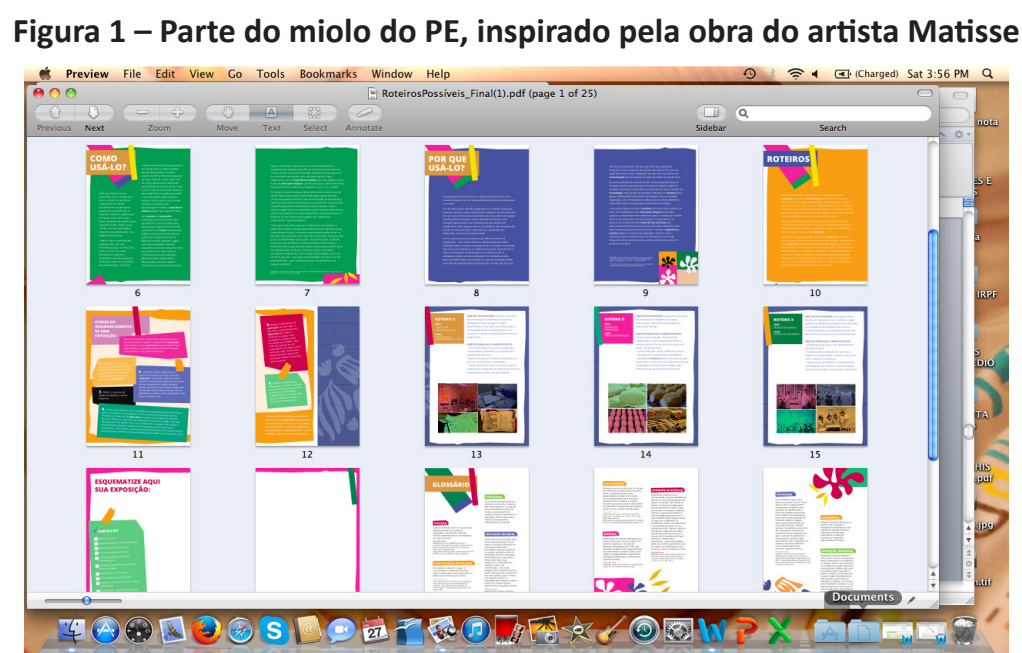

Fonte: Elaborada pela autora, baseada em trabalho anterior (CAGLIARI; ZUCOLOTTO, 2019).

\section{Experenciando "Roteiros Possíveis" em aula}

Professores de cursos técnicos, Educação de Jovens e Adultos (EJA) e superiores foram convidados a testar o PE em aula. Após o uso do material, que foi disponibilizado em PDF e impresso, os docentes foram convidados a responder um questionário aberto, onde poderiam escrever suas percepções a partir de perguntas avaliativas sobre as contribuições do PE.

Apesar de muitos professores terem sido convidados, houve baixa adesão de voluntários docentes e duas professoras concordaram em utilizar o material em aula, pois acreditaram que o PE associado as suas práticas poderiam contribuir para uma formação integral de seus educandos e si próprias (FREIRE, 1988; RAMOS, 2011). Uma delas aplicou o PE com duas turmas de diferentes semestres de uma disciplina com prática laboratorial, de um curso técnico em nível médio. A proposta foi realizada pelo grupo veterano, que preparou uma série de fotografias tiradas durante as aulas de laboratório no semestre anterior, de 2018/2, nas quais foram registrados processos químicos obtidos nas práticas. A exposição foi pensada pela docente em conjunto com os educandos, como uma curadoria compartilhada. Partindo das imagens mencionadas, expuseram digitalmente uma animação projetada na parede do corredor do andar onde ficam os laboratórios. No formato animado, fotos feitas pelos estudantes no semestre anterior foram manipuladas de forma bem-humorada e viraram memes, gifs ou tiveram a adição de emojis para relatar como são algumas situações vividas no laboratório. A intenção da professora era provocar nos calouros, público-alvo da mostra, uma curiosidade investigativa em relação à disciplina (Figura 2). 
Figura 2 - Exposição da animação criada pelos estudantes veteranos

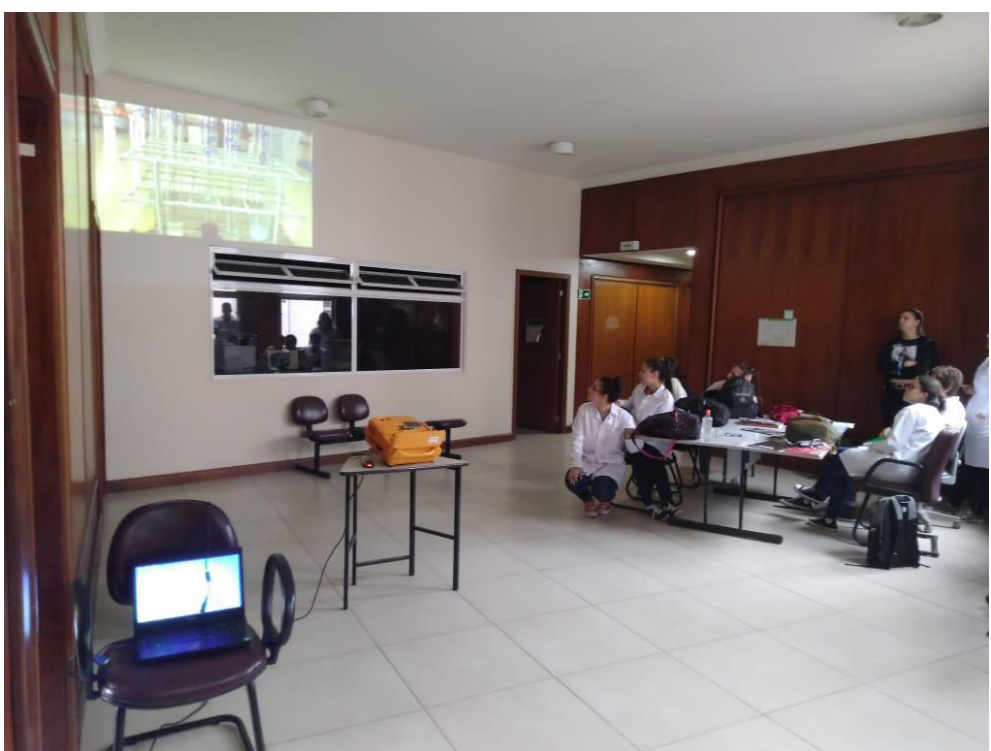

Fonte: Acervo da autora, de autoria da professora participante (2019).

Segundo relato da professora, o vídeo teve um efeito motivador para os educandos, uns relembraram as aulas no laboratório e outros, mesmo sem compreender tudo, ficaram curiosos com o porvir. A docente comentou que pensa em tornar o PE um recurso didático para fazer uma espécie de histórico do curso, um memorial, no qual os estudantes realizam registros e depois criam uma sequência animada a ser apresentada, a qual poderá até mesmo ser apresentada na formatura.

A outra professora que utilizou "Roteiros Possíveis: criando exposições no espaço de Educação Profissional e Tecnológica” em aula decidiu realizar um projeto de exposição envolvendo quatro turmas, de diferentes níveis, que teria como fio condutor o estudo de autores clássicos da disciplina que ministra. A docente atua no campus Porto Alegre lecionando no EJA, nos técnicos subsequentes e também em um curso superior de tecnologia. Juntamente com estagiários de licenciatura, a professora propôs às turmas que realizassem pesquisas sobre determinados autores e sistematizassem o conhecimento no formato de cartazes (banners) que comporiam uma exposição no átrio do campus tendo todas as turmas, de diferentes níveis de ensino, como participantes. Enquanto curadora, a docente quis fazer uso do conceito de verticalização do ensino ${ }^{3}$ para trabalhar o mesmo tema em diferentes turmas com diferentes complexidades, a fim criar uma mostra com banners no átrio do campus.

Ao todo, foram quase oito semanas de envolvimento, entre apresentação da proposta de trabalho e abertura da exposição para o público, que teve duração de dois dias e contou com a mediação realizada por alguns educandos, fato que gerou certa ansiedade nos participantes, pois para muitos, seria a primeira vez que iriam expor e se expor, mediando a mostra para os visitantes. Nessa etapa, observou-se o gradual envolvimento e a culminação da experiência estética na montagem da exposição e no dia seguinte, quando a mostra já estava aberta ao público. Uma das estudantes confessou à professora que não fazia ideia de como aquele trabalho seria transformador, pois nunca pôde mostrar aos outros o que estava aprendendo na escola e, finalmente, com a exposição, pode mostrar e mostrar-se. Foi um grande desafio para os estudantes e para a professora, porém, aos poucos foi-se compreendendo o que seria a mostra e o crescente envolvimento dos estudantes na criação do material foi percebido, contribuindo para o sentimento de autoria e autonomia observado no fim do processo.

$\mathrm{Na}$ etapa final, a montagem da exposição e a abertura da mostra, os educandos sentiam-se duplamente expostos: seus conhecimentos materializados nos banners e seus corpos no espaço expositivo do átrio

3. O termo, para os Institutos Federais, diz respeito ao fazer docente atuante em diferentes níveis de ensino, onde há o compartiIhamento de espaços pedagógicos com os estudantes e a construção de itinerários formativos, do nível técnico à pós-graduação. 
do campus Porto Alegre, visíveis para todos que entravam no prédio. Os estudantes estavam também expostos, se modificando através dessa experiência estética, que criou deslocamentos nesses indivíduos ao possibilitar pensar sobre outros modos de ser no espaçotempo, ao se apropriarem do conhecimento e mostrarem para os visitantes da mostra suas produções, ao verem-se ocupando um lugar diferente, desempenhando novos papéis (LARROSA, 2002; PEREIRA, 2011).

A exposição e todo o seu processo desenvolveram nos participantes desafios de pesquisa, de trabalho em grupo, de autonomia, de resgate de autoestima dos educandos e de articulação pedagógica docente. A professora concluiu que a mostra deu visibilidade aos educandos, sujeitos que, devido a diferentes histórias de vida, não raro são invisíveis socialmente, e buscam na escolarização, mesmo que tardia, reconhecimento (Figura 3).

Figura 3 - Vista da montagem da exposição realizada pelos estudantes do PROEJA, no átrio do campus

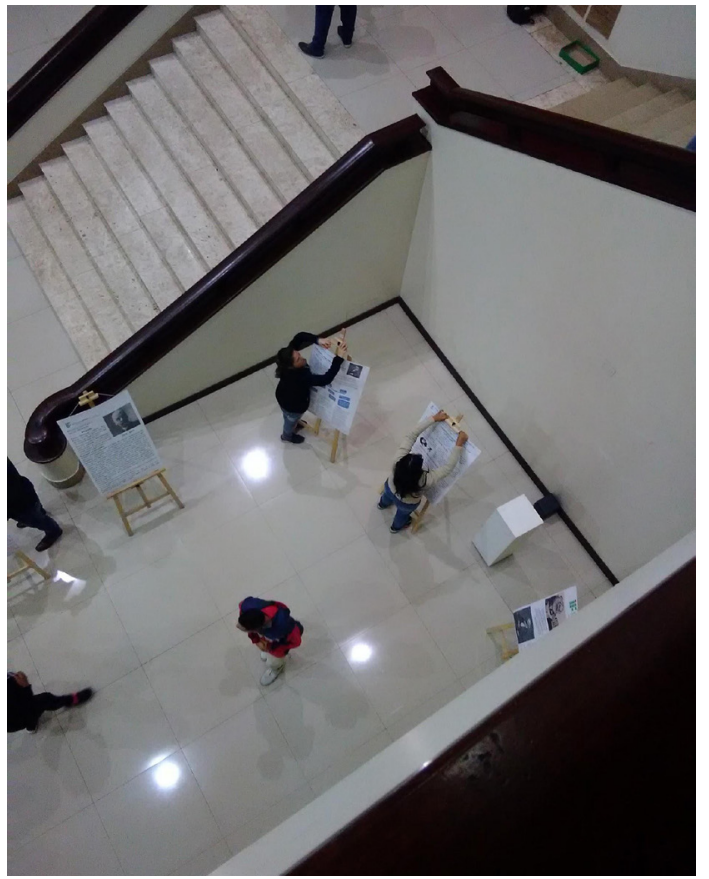

Fonte: Acervo da autora.

\section{Considerações finais}

Os usos do PE em aula revelaram que as lógicas e os saberes das práticas na experiência educativa, para acontecerem, ainda necessitam ser mediadas por operações de categorização, tematização e organização. Essa sistematização é própria do ambiente de ensino formal e se faz importante, no entanto, tão fundamental quanto ou complementar a isso, é o sentido de realidade que se dá ao que se faz para sentir-se pertencente ao espaçotempo habitado pelos sujeitos da EPT, nas situações expostas. Quanto à afirmação da ocorrência de experiências estéticas nos processos relatados, pode-se dizer que, dadas as muitas subjetividades que envolvem o experienciar-se e a comunicação dessa experiência, alguns participantes criaram estratégias e reivindicaram para si a experiência educativa como uma experiência estética, em alguma maneira sentiram-se parte, modificaram-se e transformaram-se a partir do que foi vivido (LARROSA, 2002, 2018).

Conclui-se que o PE sozinho não é suficiente para transformar o espaçotempo em experiência estética, o fator humano e as condições de trabalho são condicionantes para o êxito do material. Além disso, é preciso conhecer o que é a EPT para entender os sujeitos que dela fazem parte e o universo de ensino-aprendizagem que ali existe. Ao fim desta trajetória é possível depreender que a produção de materiais educativos como "Roteiros Possíveis" pode contribuir para um caminho novo na EPT se associado aos desejos de seus sujeitos, que almeja o desenvolvimento estético como elemento constituinte da formação humana e integral. 


\section{Referências}

ALVES, Nilda. Imagens das escolas: sobre redes de conhecimentos e currículos escolares. Educar em Revista, Curitiba, n. 17, p. 53-62, jun. 2001. Disponível em: https://www.scielo.br/scielo.php?script=sci_arttext\&pid=S0104-40602001000100005\&lng= en\&nrm=iso. Acesso em: 24 jun. 2018.

FREIRE, Paulo; SHOR, Ira. Medo e ousadia: o cotidiano do professor. 9. ed. Rio de Janeiro: Paz e Terra, 1986.

FREIRE, Paulo. Pedagogia do Oprimido. Rio de Janeiro: Paz e Terra, 1988.

GADOTTI, Moacir. Convite à leitura de Paulo Freire. São Paulo: Scipione, 1991.

GADOTTI, Moacir. Qualidade na educação: uma nova abordagem. São Paulo: Instituto Paulo Freire, 2010.

HERMANN, Nadja. Razão e sensibilidade: notas sobre a contribuição do estético para a ética. Educação e Realidade, Porto Alegre, v. 27, n. 1, p. 11-26, jan./jun. 2002. Disponível em: https://seer.ufrgs.br/educacaoerealidade/article/ view/25936. Acesso em: 30 nov. 2017.

KAPLÚN, Gabriel. Material educativo: a experiência de aprendizado. Comunicação \& Educação, São Paulo, ano 9, n. 27, p. 46-60, maio/ago. 2003.

LARROSA, Jorge. Notas sobre a experiência e o saber de experiência. Revista Brasileira de Educação, Rio de Janeiro, n. 19, p. 20-28, abr. 2002.

LARROSA, Jorge. Tremores: escritos sobre experiência. Belo Horizonte: Autêntica, 2018.

PEREIRA, Marcos Villela. Contribuições para entender a Experiência Estética. Revista Lusófona de Educação, Portugal, v. 18, n. 18, p. 111-123, dez. 2011.

RAMOS, Marise. Políticas e diretrizes para a educação profissional no Brasil. Curitiba: Instituto Federal do Paraná, 2011.

Data de submissão: 05/06/2020

Data de aceite: 02/07/2020 